\title{
Correction to: TREC Screening for WHIM Syndrome
}

\section{Martin Oman Evans II ${ }^{1}$ (D) Maureen M. Petersen ${ }^{2} \cdot$ Amer Khojah $^{3} \cdot$ Soma C. Jyonouchi $^{4} \cdot$ George S. Edwardson $^{5}$. Yasmin West Khan ${ }^{6}$. James Albert Connelly ${ }^{6}$. David Morris ${ }^{7}$. Shamik Majumdar ${ }^{8}$. David H. McDermott ${ }^{8}$. Jolan E. Walter ${ }^{9,10} \cdot$ Philip M. Murphy ${ }^{8}$}

Published online: 28 January 2021

(C) Springer Science+Business Media, LLC, part of Springer Nature 2021

\section{Correction to: Journal of Clinical Immunology https://doi.org/10.1007/s10875-020-00921-4}

The original article contained errors in Tables 1 and 3. The 3 entries of Table 1 were mistakenly changed to "None" instead of "TRECs/uL:29","TRECs/uL:250" and "Ct:37.7". While in Table 3, "IgC" should be "IgG".
The online version of the original article can be found at https://doi.org/ 10.1007/s10875-020-00921-4

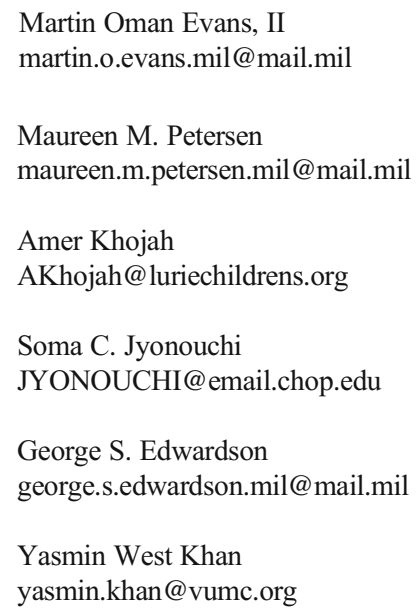

The original version has been corrected.

Publisher's Note Springer Nature remains neutral with regard to jurisdictional claims in published maps and institutional affiliations.
James Albert Connelly

james.a.connelly@vumc.org

David Morris

MorrisD1@childrensdayton.org

Shamik Majumdar

shamik.majumdar@nih.gov

David H. McDermott

dmcdermott@niaid.nih.gov

Jolan E. Walter

jolanwalter@usf.edu

Philip M. Murphy

pmm@nih.gov

Extended author information available on the last page of the article 


\section{Affiliations}

Martin Oman Evans II ${ }^{1}$ (D) Maureen M. Petersen ${ }^{2} \cdot$ Amer Khojah $^{3} \cdot$ Soma C. Jyonouchi $^{4} \cdot$ George S. Edwardson $^{5} \cdot$

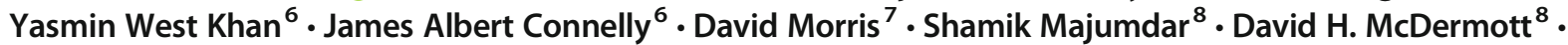
Jolan E. Walter ${ }^{9,10}$. Philip M. Murphy ${ }^{8}$

1 Blanchfield Army Community Hospital, Fort Campbell, KY, USA

2 Walter Reed National Military Medical Center, Bethesda, MD, USA

3 Ann \& Robert H. Lurie Children's Hospital of Chicago, Chicago, IL, USA

4 Children's Hospital of Philadelphia, Philadelphia, PA, USA

5 Wright-Patterson Medical Center, Wright-Patterson Air Force Base, Wright-Patterson AFB, OH, USA

6 Vanderbilt University Medical Center, Nashville, TN, USA
7 Dayton Children's Hospital, Dayton, OH, USA

8 National Institute of Allergy and Infectious Diseases, National Institutes of Health, Bethesda, MD, USA

9 University of South Florida and Johns Hopkins All Children's Hospital, St. Petersburg, FL, USA

10 Massachusetts General Hospital for Children, Boston, MA, USA 